\title{
The application of organics promotes arsenic methylation in paddy soils
}

\author{
G.L. Duan ${ }^{1}$, Y.P. Yang ${ }^{1}$, X.Y. Yi ${ }^{1}$ \& Y.G. Zhu ${ }^{1,2}$ \\ ${ }^{1}$ Research Center for Eco-Environmental Sciences, Chinese Academy of Sciences, Beijing, P.R. China \\ ${ }^{2}$ Institute of Urban Environment, Chinese Academy of Sciences, Xiamen, P.R. China
}

\begin{abstract}
Arsenic (As) accumulation in rice grains poses critical health risk for populations whose staple food is rice. Organics could affect As transformation and volatilization in soil, and subsequently affect As accumulation and speciation in rice grains. Straw application significantly promoted As release from soil and As methylation, also enhanced As volatilization from soil. However, straw application significantly increased DMA accumulation in polished rice grains. Straw biochar application significantly decreased inorganic As concentration in polished grains, but did not significantly affect As methylation and DMA accumulation. Fulvic acid addition significantly increased As bio-availability in the soil, and high level of humic acid addition significantly enhanced As volatilization.
\end{abstract}

\section{INTRODUCTION}

Arsenic (As) is a toxic metalloid, and inorganic As is classified as a class 1 and non-threshold carcinogen (Smith et al., 2002). Arsenic ubiquitously exists in the environment, and paddy fields are widely contaminated with As (Zhao et al., 2015). Arsenic in paddy soil can be readily taken up by rice roots, and accumulated to rice grains, the staple food for more than half of the world's population and two thirds of the Chinese population. It has been reported that rice consumption constitutes a major source of dietary intake of inorganic As for populations whose staple food is rice (Li et al., 2011). Therefore, it is of great significance to reduce As accumulation in rice grains (Zhu et al., 2014).

Different As speciation has different toxicity, generally, inorganic As (such as arsenite and arsenate) is more toxic than organic As (such as MMA and DMA). In rice grains, arsenite and DMA are the predominant arsenic species. It has been demonstrated that rice plants lack the ability to methylate arsenic, and DMA in rice grain is derived from the soil through microorganism-mediated methylation (Lomax et al., 2012). Therefore, promoting the process of arsenic methylation in paddy, and subsequently decrease the proportion of arsenite in rice gains are of great importance for safe rice production at As contaminated fields. In addition, the last product of As methylation is TMA, which is volatile gas. Thus, enhancing As volatilization could be a potential strategy for As bioremediation of paddy soil.

\section{METHODS/EXPERIMENTAL}

\subsection{Rice cultivation}

Rice straw is the main by-product of rice production. It has been reported that straw incorporation could enhance As methylation. Therefore, pot experiments were carried out to investigate the effects of straw incorporation on As volatilization. For this experiment, $4 \mathrm{~kg}$ As contaminated soil, which was sampled from Qiyang city (Hunan province, China), The As concentration of the soil was $84.7 \mathrm{mg} \mathrm{kg}^{-1}$. The treatments were as follows: (1) Control (No straw biochar nor straw); (2) $1 \%$ straw biochar; (3) $2 \%$ straw biochar; (4) 4\% straw biochar; (5) 1\% straw; (6) 2\% straw; (7) $4 \%$ straw. Fertilization and watering were managed according to the local practices. After grain mature, rice grains were harvested for As concentration and speciation analysis by HPLC-ICP-MS.

\subsection{Soil incubation with organics}

To understand how organics affect As transformation in soil, humic acid and fulvic acid were incubated with As contaminated soil, and the dynamic As transformation and volatilization was monitored. In this experiment, $200 \mathrm{~g}$ soil (the same as pot experiment) was mixed with humic acid and fulvic acid at 5 levels: $0,2,5,10,15 \mathrm{mg} \mathrm{kg}^{-1}$ soil. Then $240 \mathrm{~mL}$ deionized water was added to the flask and keeping a water layer about $2-3 \mathrm{~cm}$ above the soil surface during the experiment. Every week, the volatilized gas was sampled. 
As in the volatilized gas was trapped and the amount was analyzed.

\subsection{Volatile As collection}

Arsenic volatilizing from each pot was collected with silica gel rinsed with $2 \% \mathrm{AgNO}_{3}$ for one week at 4 different growing stages. After sampling, the trapping tubes were collected, and then the silica gel in the trapping tubes was sampled and digested. Total As concentration was measured by ICP-MS.

\section{RESULTS AND DISCUSSION}

\subsection{Straw application increased DMA accumulation in polished rice grains}

Straw application significantly increased total As concentration in polished grains and husk, while decreased total As in straw, and no significant effects on As accumulation in root. In polished grains, total As concentration could be increased by 4 -fold by $4 \%$ straw application. Straw biochar application had no significant effect on total As concentration in polished grains.

In polished grains, As(V), As(III) and dimethylarsenate (DMA) were detected. Straw application significantly increased DMA concentration in polished grains. At the treatment of $4 \%$ straw application, DMA concentration in polished grains increased by about 8-fold when compared to control. Straw biochar application significantly decreased inorganic As concentration in polished grains but did not significantly affect DMA concentration.

\subsection{Straw application enhanced As volatilization from paddy soil}

During the whole rice-growing season, small amounts of volatile As were detected in the control and straw biochar treatments, and straw biochar did not affect As volatilization, when compared with the control. However, straw application significantly enhanced the As volatilization from paddy soil. At seedling stage, As volatilization apparently increased with increasing dose of straw added to soil. Compared with control, the treatment of $4 \%$ straw application increased As volatilization by 166,64 and 12 times at seedling, tillering, and heading stages, respectively. Arsenic volatilization reached the maximum rate at seedling stage, then showed a decreasing trend with the rice growth stage. At maturing stage, the fluxes of volatile As were less than one-tenth of that at seedling stage.

\subsection{Addition of humic acid and fulvic acid promoted As methylation in paddy soil}

Without organics addition, As concentration in soil solution was increased with the incubation time, and reached maximum concentration at day 14 , then declined. With addition of humic acid, As concentration in soil solution showed similar dynamic pattern to control. However, with addition of fulvic acid, As concentration in soil solution increased within 14 days incubation, and then kept at high levels until the experiment was finished after 28 days incubation.

Humic acid and fulvic acid addition increased As bioavailability in soil. Total As concentration in soil solution was increased by organics addition, especially by fulvic acid addition. When soil was incubated with $10 \mathrm{mg} \mathrm{kg}^{-1}$ fulvic acid for 28 days, arsenite concentration in soil solution increased by about 5-fold, when compared with control. Arsenite was the dominated As species in soil solution.

Humic acid and fulvic acid addition enhanced As methylation in the soil. Arsenic volatilization was significantly enhanced by higher humic acid $\left(>5 \mathrm{mg} \mathrm{kg}^{-1}\right)$ addition, and lower fulvic acid $\left(<10 \mathrm{mg} \mathrm{kg}^{-1}\right)$ addition. With the same addition level, the fluxes of volatile As collected from humic acid treatments were higher than that from fulvic acid treatments. MMA and DMA concentration in soil solution were significantly increased by fulvic acid addition. These results suggested that, compare to humic acid, fulvic acid was more efficient for activating As in soil, but the activated As in soil solution was not readily for As volatilization.

\section{CONCLUSIONS}

Straw application promoted As release from soil and As methylation, enhanced As volatilization, but increased DMA accumulation in polished rice grains. Fulvic acid addition significantly increased As bioavailability in the soil, but the activated As in soil solution was not readily for As volatilization.

\section{ACKNOWLEDGEMENTS}

This research was funded by the National Natural Science Foundation of China (grant no. 41371458 and 21677157), and the special fund for agro-scientific research in the public interest (grant no. 201403015).

\section{REFERENCES}

Li, G., Sun, G.X., Williams, P.N., Nunes, L. \& Zhu, Y.G. 2011. Inorganic arsenic in Chinese food and its cancer risk. Environ. Int. 37(7): 1219-1225.

Lomax, C., Liu, W.J., Wu, L.Y., Xue, K., Xiong, J., Zhou, J., McGrath, S.P., Meharg, A., Miller, A.J. \& Zhao, F.J. 2012. Methylated arsenic species in plants originate from soil microorganisms. New Phytol. 193(3): 665-672.

Smith, A.H., Lopipero, P.A., Bates, M.N. \& Steinmaus, C.M. 2002. Public health - arsenic epidemiology and drinking water standards. Science 296: 2145-2146.

Zhao, F.J., Ma, Y., Zhu, Y.G., Tang, Z. \& McGrath, S.P. 2015. Soil contamination in China: current status and mitigation strategies. Environ. Sci. Technol. 49(2): 750-759.

Zhu, Y.G., Yoshinaga, M., Zhao, F.J. \& Rosen, B.P. 2014. Earth abides arsenic biotransformations. Annu. Rev. Earth Planet. Sci. 42: 443-467. 